\title{
Molecular characterization of uterine clear cell carcinoma
}

\author{
Hee-Jung $\mathrm{An}^{1, *}$, Sanjay Logani ${ }^{2, *}$, Christina Isacson ${ }^{3}$ and Lora H Ellenson ${ }^{1}$ \\ ${ }^{1}$ Department of Pathology and Laboratory Medicine, Weill Medical College of Cornell University, New York, \\ NY, USA; ${ }^{2}$ Department of Pathology, Emory University Hospital, Atlanta, GA, USA and ${ }^{3}$ Department of \\ Pathology, Virginia Mason Medical Center, Seattle, WA, USA
}

\begin{abstract}
Clinicopathological studies support a broad classification of endometrial carcinoma into two major types, designated as type I and type II, which correlate with their biological behavior. More recently, molecular studies have provided further insights into this classification scheme by elucidating the genetic events involved in the development and progression of endometrial carcinoma. Microsatellite instability and mutations in the PTEN gene have been widely associated with type I (endometrioid) endometrial carcinoma, while p53 mutations have been identified in the majority of type II endometrial carcinoma, of which uterine serous carcinoma is the prototype. Uterine clear cell carcinoma (UCC) is an uncommon variant of endometrial carcinoma, and clinicopathological studies have produced conflicting results regarding its biological behavior with 5-year survival ranging from 21 to $75 \%$. The molecular characteristics of endometrioid and serous carcinoma have been studied extensively; however, there have been few molecular genetic studies of the clear cell subtype. In this study, we evaluated 16 UCCs (11 pure and 5 mixed) for mutations in the p53 gene, PTEN gene and for microsatellite instability. Although we found that these alterations were uncommon in pure clear cell carcinomas, all three were identified. In addition, two cases of mixed serous and clear cell carcinoma showed an identical mutation of the $p 53$ gene in the histologically distinct components and one case of mixed clear cell and endometrioid carcinoma had identical mutations in the PTEN and p53 genes, and microsatellite instability in both components. Our data suggest that UCC represent a heterogeneous group of tumors that arise via different pathogenetic pathways. Additional molecular studies of pure clear cell carcinoma are required to further elucidate the genetic pathways involved in its development and progression.

Modern Pathology (2004) 17, 530-537, advance online publication, 20 February 2004; doi:10.1038/modpathol.3800057
\end{abstract}

Keywords: uterine clear cell carcinoma; PTEN mutation; microsatellite instability; p53 mutation

Clear cell carcinoma of the endometrium has been recognized as a distinct, but uncommon, histologic variant accounting for only $1-5 \%$ of all endometrial adenocarcinoma. The proposed dualistic model of endometrial carcinoma pathogenesis, of which uterine endometrioid carcinoma (UEC) and uterine serous carcinoma (USC) are prototypic examples, is based on clinicopathologic differences between the two tumor subtypes ${ }^{1}$ and supported by immunohistochemical and molecular genetic studies. $^{2-4}$ Type I tumors are thought to arise in the setting of estrogenic stimulation and are

Correspondence: Correspondence: Dr LH Ellenson, MD, Department of Pathology, Weill Medical College of Cornell University, 525 East 68th Street, Starr 1005, New York, NY 10021, USA.

E-mail: lhellens@med.cornell.edu

${ }^{*}$ Both authors contributed equally to this work.

Received 23 June 2003; revised 5 November 2003; accepted 11

November 2003; published online 20 February 2004 endometrioid in histology, while type II tumors are unrelated to estrogen exposure, arising in a background of atrophy and often serous in histology. The most common genetic alterations in UEC are PTEN mutations $(30-50 \%)^{5}$ and microsatellite instability (MI) $(20 \%),{ }^{6-8}$ while in USC mutations of the p53 gene are found in approximately $90 \%$ of cases. ${ }^{3,9,10}$

Recent immunohistochemical studies using p53, Ki67, estrogen and progesterone receptors performed on uterine clear cell carcinoma (UCC) have suggested differences in the molecular events that underlie the pathogenesis of this subtype. ${ }^{11}$ To date, the molecular characteristics of UCC have not been studied and the pathogenetic pathway of this tumor type is unclear. In the current study, we analyzed a series of UCC for PTEN and p53 gene mutations and MI to determine its relationship, if any, to the two most common histologic types of endometrial carcinoma. 


\section{Materials and methods}

\section{Clinical Specimens}

A total of 16 cases of clear cell carcinoma of the endometrium, including 11 pure UCC, two cases of mixed UCC/ UEC, two cases of mixed UCC/ USC and one case of malignant mesodermal mixed tumor (MMMT) with a UCC component, were selected from the surgical pathology files of the New York Presbyterian Hospital-Cornell Medical Center from 1979 to 1999. Of the 16 cases, 14 were hysterectomy specimens, nine of which also included previous endometrial curettage specimens. Two cases (cases 1 and 3) were curettage specimens alone.

\section{DNA Extraction}

DNA was extracted from paraffin-embedded paired normal and tumor tissue using microdissection. In the mixed cases, each histologically distinct component was separately microdissected. All cases were microdissected to ensure greater than $85 \%$ tumor cells.

\section{Sequence Analysis of PTEN and p53 Genes}

Extracted tumor DNA was analyzed for mutations in the PTEN and p53 gene using exon-specific polymerase chain reaction (PCR) amplification and direct DNA sequencing. All cases were assayed for intragenic mutations in exons $3,4,5,7$ and 8 of the PTEN gene and in exons 5, 6, 7 and 8 of the p53 gene. A volume of $3-6 \mu \mathrm{l}$ of PCR product was purified by an enzymatic method, and submitted for direct DNA sequence analysis using the ThermoSequenase Kit (Amersham Life Science, Cleveland, $\mathrm{OH}$, USA) with the incorporation of ${ }^{33} \mathrm{P}$-labeled dideoxynucleotides. The radiolabeled PCR products were fractionated by electrophoresis on a denaturing $6 \%$ polyacrylamide gel and visualized by autoradiography. All cases with mutations were re-amplified and re-sequenced to ensure reproducibility.

\section{Microsatellite Instability Analysis}

Microsatellite instability (MI) was analyzed in paired normal and tumor tissue using eight microsatellite loci on four different chromosomes. Seven anonymous dinucleotide microsatellite loci (D2S119, D2S123, D2S147, D10S197, D13S175, D18S58 and D18S69) and one mononucleotide microsatellite locus (Bat 26) were analyzed. Radiolabeled [ $\left.{ }^{32} \mathrm{P}\right] \mathrm{PCR}$ products were visualized following electrophoretic fractionation on $6 \%$ polyacrylamide/8 M urea gels by autoradiography. The tumors were determined to be MI-positive when an electrophoretic shift of the PCR product, compared with that of normal tissue DNA, was detected in at least two of the loci.

\section{Immunohistochemical Expression of p53 Protein}

p53 protein was detected immunohistochemically using a mouse p53 monoclonal antibody (clone 1801, BioGenex, San Ramon, CA, USA) at a dilution of 1:150 with a 50-min incubation at room temperature on a TechMate 500 automated stainer (Ventana, Tucson, AZ, USA). The p53 staining was scored based on the intensity of nuclear staining and number of cells stained according to a subjective grading system. The staining intensity was divided into four categories $0=$ negative, $1=$ weakly: positive, $2=$ moderately positive and $3=$ strongly positive. The quantity of cells stained was scored as: $0=$ no staining, $1=1-10 \%, 2=11-50 \%, 3=51-80 \%$ and $4=>81 \%$ tumor nuclei stained. An immunoreactive score was rendered as a product of the scores obtained for staining intensity and quantity. A total score of 0 was considered negative, 1-3: weak, 4-7: moderate and 8-12: strong immunoreactivity.

\section{Results}

\section{PTEN Sequence Analysis}

Two of 16 UCC (cases 1 and 3) could not be completely analyzed because there was insufficient DNA available to accomplish PCR amplification of the five exons. PTEN gene mutations (Table 1) were identified in three of 14 (21\%) UCC. Of the three mutation-positive tumors, two were pure UCC and one case (case 10) was mixed UCC/ UEC. Of the two pure UCC with PTEN mutations, one (case 2) demonstrated a missense mutation, which was a $G$ to A transition at codon 307 , resulting in a glutamic acid to lysine substitution that was not present in matched normal DNA (Figure 1a). The other pure UCC (case 4) showed a frame-shift mutation caused by the deletion of one A at codon 322 in exon 8 . In the mixed UCC/ UEC (case 10), both morphologic components had identical nonsense mutation resulting from a $\mathrm{C}$ to $\mathrm{T}$ transition at codon 233 (Figure 1b).

Table 1 PTEN mutation analysis

\begin{tabular}{rlll}
\hline \multirow{2}{*}{ Case } & & \multicolumn{2}{l}{ PTEN Mutation } \\
\cline { 3 - 4 } & & Exon (codon) & Type \\
\hline 2 & UCC & Ex $8(307)$ & Missense: GAG - AAG (Glu-Lys) \\
4 & UCC & Ex $8(322)$ & Frameshift (A deletion) \\
10 & UCC & Ex $7(233)$ & Nonsense: CGA-TGA (Arg-stop) \\
& UEC & Ex $7(233)$ & Nonsense: CGA-TGA (Arg-stop)
\end{tabular}

UCC, uterine clear cell carcinoma; UEC, uterine endometrioid carcinoma. 
a

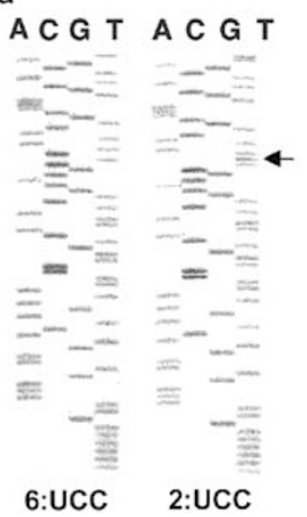

b

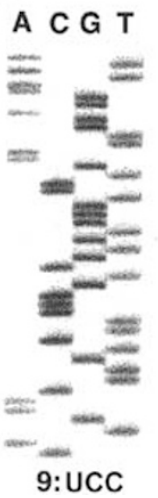

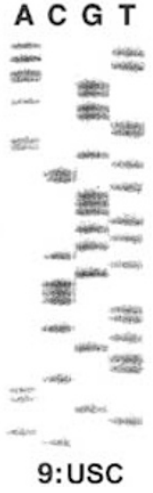

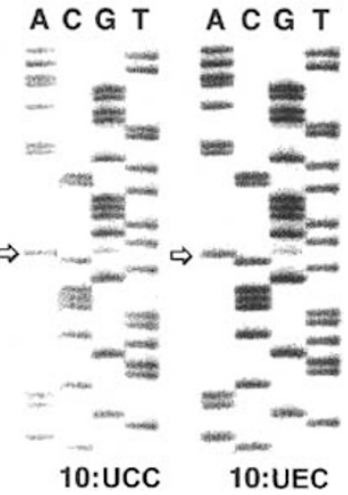

Figure 1 PTEN sequence analysis. (a) PTEN exon 8 sequence analysis (antisense ) in case 2 shows a missense mutation (G to A transition) resulting in glutamic acid (GAG) to lysine (AAG) substitution (arrow), not present in wild-type sequence as demonstrated by case 6. (b) PTEN exon 7 sequence analysis (antisense) in case 10 shows a nonsense mutation (C to $\mathrm{T}$ transition) resulting in stop codon (TGA) in both UCC and UEC components (arrow) as compared to the wild-type sequence in case 9.

Table 2 Microsatellite instability summary

\begin{tabular}{|c|c|c|c|c|c|c|c|c|c|}
\hline \multicolumn{2}{|c|}{ Case } & \multirow{2}{*}{$\frac{D 2 S 119}{+}$} & \multirow{2}{*}{$\begin{array}{c}D 2 S 123 \\
+\end{array}$} & \multirow{2}{*}{$\begin{array}{c}D 2 S 147 \\
+\end{array}$} & \multirow{2}{*}{$\begin{array}{c}\text { D10S197 } \\
+\end{array}$} & \multirow{2}{*}{$\frac{D 13 S 175}{-}$} & \multirow{2}{*}{$\frac{D 18 S 58}{+}$} & \multirow{2}{*}{$\begin{array}{c}\text { D18S69 } \\
+\end{array}$} & \multirow{2}{*}{$\begin{array}{r}B 26 \\
+\end{array}$} \\
\hline 2 & UCC & & & & & & & & \\
\hline 5 & UCC & - & - & NA & - & - & - & $\mathrm{LOH}$ & - \\
\hline \multirow[t]{2}{*}{6} & UCC & - & - & - & - & - & $\mathrm{LOH}$ & - & - \\
\hline & USC & - & - & $\mathrm{LOH}$ & - & - & - & - & - \\
\hline \multirow[t]{2}{*}{10} & UCC & - & + & + & + & + & + & + & + \\
\hline & UEC & - & + & + & + & + & + & + & + \\
\hline 15 & UCC & NA & - & NA & - & - & $\mathrm{LOH}$ & - & - \\
\hline \multirow[t]{3}{*}{16} & UCC & & & & & & & & \\
\hline & UT & NA & - & - & - & - & - & - & - \\
\hline & $\mathrm{OM}$ & NA & - & - & - & $\mathrm{LOH}$ & - & - & - \\
\hline
\end{tabular}

LOH, loss of heterozygosity; NA, not analyzed; UT, uterus; OM, omental metastasis.

\section{Microsatellite Instability}

Of 16 UCC, 14 were available for MI analysis; two cases (cases 1 and 3) did not have paired normal tissue (Table 2). All cases were informative at six or more microsatellite loci. MI phenotype was identified in two of $14(14 \%)$ cases, one pure UCC and the other a mixed UCC/ UEC (Figures 2a and 2b). Both cases showed shifts at seven of eight microsatellite loci. Additionally, we found loss of heterozygosity $(\mathrm{LOH})$ in several microsatellite loci in four cases. In one case of mixed UCC/USC, LOH was shown at different loci in the two different components (Figure 2c).

\section{p53 Immunohistochemical Analysis}

Strong nuclear expression of p53 protein in the majority of tumor cells was identified in five cases: one of 11 pure UCC, both mixed UCC/ USC cases, one of two mixed UCC/ UEC cases (Figures 3a-d) and the UCC/ MMMT case (Table 3). Only one mixed case had a low immunoreactive score: negative immunoreactivity in the UCC component and weak immunoreactivity in the UEC component. Six pure
UCC cases showed weak to moderate staining, and four pure UCC cases were negative.

\section{p53 Sequence Analysis}

p53 gene mutations were identified in one of 11 (9\%) pure UCC, two mixed UCC/ USC (Figure 4a), 1 mixed UCC/ UEC (Figure 4b) and one mixed UCC/ MMMT (Table 3). Both morphologic components of each of the mixed carcinomas showed the same $p 53$ mutation. Of five mutations, three (cases 9, 10,14) occurred at CpG dinucleotides 'hot spots' of the p53 gene. In the other two remaining cases, one (case 5) showed a missense mutation ( $\mathrm{T}$ to $\mathrm{G}$ transversion) at codon 197, resulting in valine to glycine amino-acid substitution and the other (case 6) was an in-frame deletion of $16 \mathrm{bp}$ with a $1 \mathrm{bp}$ insertion from codon 290 to 295 of exon 8. One pure UCC (case 15) showed a silent A to $G$ transition at codon 213, which was present in the matched normal tissue. All cases with a mutation demonstrated moderate to strong expression of p53 by immunohistochemical staining. Only one case showing strong p53-immunoreactivity (case 1) did not contain a p53 mutation in the exons examined. 


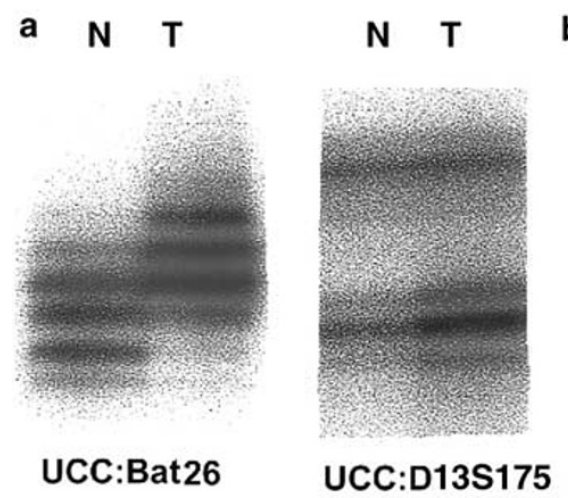

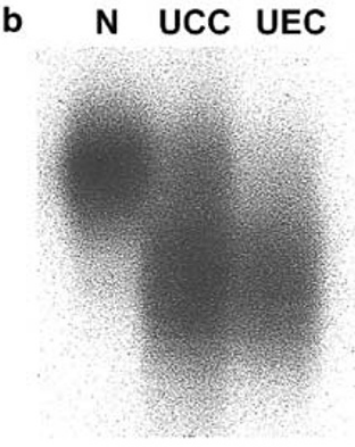

UCC:Bat 26
N UCC UEC

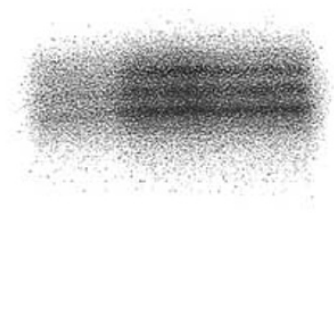

UCC:D2S119

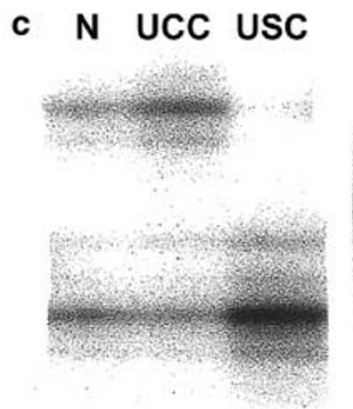

UCC:D2S147

N UCC UsC

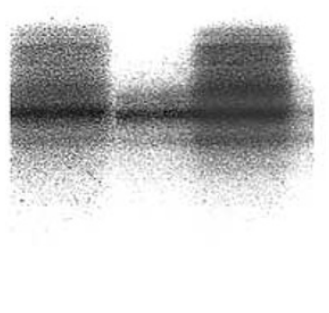

UCC:D18S58

Figure 2 Microsatellite analysis. (a) MI analysis of case 2 shows instability at Bat 26 but not at D13S175. (b) Microsatellite analysis of case 10 shows instability at Bat 26 but not at D2S119 in both UCC and UEC components. (c) Microsatellite analysis of case 6 (mixed UCC, USC) demonstrates LOH in the USC component at D2S147 and in the UCC component at D18S58.

\section{Discussion}

The biological behavior of UCC has generated controversy in the literature. ${ }^{12-23}$ It is generally considered an aggressive tumor type similar to serous carcinoma of the endometrium. However, recent studies have suggested that it has a better survival than USC. ${ }^{16,21}$ The dualistic model of endometrial carcinogenesis, initially proposed on the basis of clinicopathologic differences between endometrioid and serous subtypes of endometrial adenocarcinoma, ${ }^{1}$ has received wide support from immunohistochemical and molecular studies. ${ }^{2,3,9}$ Clear cell carcinoma, although classified along with serous adenocarcinoma due to their clinicopathologic similarities, has not been studied using molecular techniques. In an attempt to understand the molecular underpinnings and to refine our understanding of this tumor subtype, we undertook a molecular study of UCC and evaluated 11 cases of pure and five cases of mixed clear cell carcinoma of the endometrium for mutations in the p53 and PTEN genes and MI.

PTEN is a tumor suppressor gene located within chromosomal region 10q23, initially identified on the basis of $\mathrm{LOH}$ at chromosome $10 \mathrm{q} 23$ in a variety of human tumors. ${ }^{24}$ This finding, along with the observation that wild-type chromosome 10 suppresses the tumorigenicity of glioblastoma cells in mice suggested the presence of a tumor suppressor gene at this locus, subsequently identified and cloned as the PTEN gene. PTEN mutations or homozygous deletions have been identified in multiple tumor types, including prostate, breast and thyroid carcinoma. ${ }^{24}$ Tashiro et $a l^{5}$ evaluated the presence of PTEN mutations in endometrial carcinoma and found them to be present exclusively in the endometrioid subtype. Clear cell carcinomas were not evaluated in their study. Levine et $a l^{25}$ demonstrated PTEN mutations in complex atypical hyperplasia and concluded that PTEN gene mutations may be an early event in the pathogenesis of endometrioid adenocarcinoma. It is rare to find PTEN mutations in serous carcinoma ${ }^{2}$ and in one recent study ${ }^{5}$ all six serous tumors lacked detectable mutations in this gene. If clear cell carcinoma is similar in its pathogenesis to serous carcinoma, that is, type II, PTEN mutations would be expected to be low in frequency in this subtype. Indeed, nearly $80 \%$ of the UCC did not exhibit a mutation in the $P T E N$ gene in our study. In the three cases with a PTEN mutation, the patients were elderly and the adjacent endometrium did not show evidence of hyperplasia, clinical and pathologic findings more often associated with a type II tumor. Two tumors additionally showed MI. The sample size of the tumors with PTEN mutation is too small to draw any significant conclusions, but do raise the possibility 

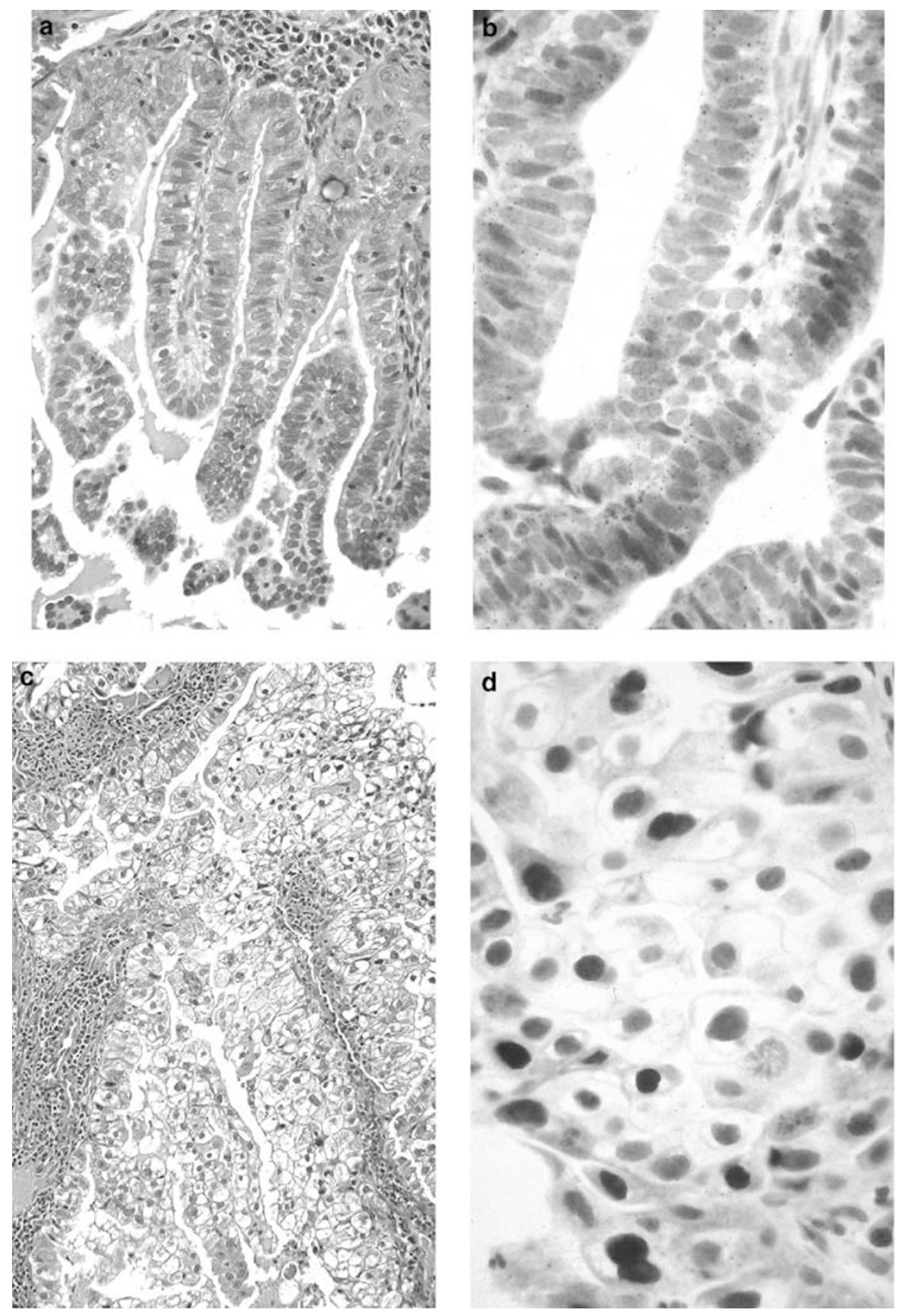

Figure 3 p53 immunohistochemical staining in a case of mixed UEC/ UCC. (a) Focus of endometrioid adenocarcinoma with (b) weak immunohistochemical expression of p53 contrasts with the (c) clear cell component showing (d) strong nuclear expression of p53 protein.

that a subset of UCC shares molecular pathways of the typical type I endometrial carcinoma. It is interesting to note that the tumor suppressor function of the PTEN protein is postulated to be derived from phosphatase catalytic domain that is encoded on exon 5 of the gene, and abnormalities in this region may be important for loss of PTEN gene function. In the study by Yaginuma et al, ${ }^{26}$ mutations in exon 5 were noted in $36 \%$ of the endometrial carcinomas studied with only one case with an abnormality on exon 7; however, the histologic type was not specified in their study. The two pure UCC cases in our study showed a mutation involving exon 8 of the PTEN gene and in the single case of mixed UCC/UEC, the mutation involved exon 7 . In this study, we chose to limit our analysis to the five exons of the PTEN gene (exons 3,4,5,7 and 8) with the highest frequency of mutations. In addition, we did not attempt to identify homozygous and/or heterozygous deletions of the PTEN gene. 
Table 3 p53 immunohistochemical staining and mutation analysis

\begin{tabular}{|c|c|c|c|c|c|c|}
\hline \multirow[t]{2}{*}{ Case } & \multirow[t]{2}{*}{ Histology } & \multicolumn{4}{|c|}{ p53 immunostaining } & p53 mutation analysis \\
\hline & & Quantity & Intensity & Score & Overall rating & Exon (Codon) Type: nucleotide (aa) change \\
\hline 1 & UCC & 4 & 3 & 12 & Strong & $\mathrm{WT}$ \\
\hline 2 & UCC & 2 & 2 & 4 & Moderate & WT \\
\hline 3 & UCC & 2 & 2 & 4 & Moderate & WT \\
\hline 4 & UCC & 1 & 3 & 3 & Weak & WT \\
\hline 5 & UCC & 3 & 2 & 6 & Moderate & Ex 6 (197) MS: GTG-GGG (Val-Gly) \\
\hline \multirow[t]{2}{*}{6} & UCC & 3 & 3 & 6 & Moderate & Ex 8 (290-295) F: 16 bp Del/1 bp In \\
\hline & USC & 4 & 3 & 12 & Strong & Ex 8 (290-295) F: 16 bp Del/1 bp In \\
\hline 7 & UCC & 0 & 0 & 0 & Negative & WT \\
\hline 8 & UCC & 2 & 1 & 2 & Weak & WT \\
\hline \multirow[t]{2}{*}{9} & UCC & 4 & 3 & 12 & Strong & Ex 8 (273) MS: CGT-TGT (Arg-Cys) \\
\hline & USC & 4 & 3 & 12 & Strong & Ex 8 (273) MS: CGT-TGT (Arg-Cys) \\
\hline \multirow{2}{*}{10} & UCC & 3 & 3 & 9 & Strong & Ex 8 (270) MS:CGC-TGC (Arg-Cys) \\
\hline & UEC & 3 & 2 & 6 & Moderate & Ex 8 (270) MS:CGC-TGC (Arg-Cys) \\
\hline 11 & UCC & 0 & 0 & 0 & Negative & WT \\
\hline \multirow[t]{2}{*}{12} & UCC & 0 & 0 & 0 & Negative & WT \\
\hline & UEC & 1 & 1 & 1 & Weak & $\mathrm{WT}$ \\
\hline 13 & UCC & 1 & 1 & 1 & Weak & WT \\
\hline \multirow[t]{3}{*}{14} & UCC & 3 & 3 & 9 & Strong & Ex 7 (248) MS: CGG-TGG (Arg-Trp) \\
\hline & MCA & 4 & 3 & 12 & Strong & Ex 7 (248) MS: CGG-TGG (Arg-Trp) \\
\hline & MSA & 4 & 3 & 12 & Strong & Ex 7 (248) MS: CGG-TGG (Arg-Trp) \\
\hline 15 & UCC & 0 & 0 & 0 & Negative & Polymorphism: CGA-CGG (Arg-Arg) \\
\hline 16 & UCC & 0 & 0 & 0 & Negative & WT \\
\hline
\end{tabular}

UCC, clear cell carcinoma; USC, serous carcinoma; UEC, endometrioid carcinoma; MCA, carcinomatous component of MMMT; MSA, sarcomatous component of MMMT; WT, wild type; MS, missense; F, frameshift; Del, deletion; In, insertion.

Table 4 Clinical and molecular genetic summary

\begin{tabular}{|c|c|c|c|c|c|c|c|}
\hline \multicolumn{2}{|c|}{ Case } & \multirow{2}{*}{$\begin{array}{c}\text { Age (years) } \\
83\end{array}$} & \multirow{2}{*}{$\begin{array}{l}\text { Adjacent endometrium } \\
\text { NA }\end{array}$} & \multirow{2}{*}{$\frac{\text { Clinical stage }}{\text { NA }}$} & \multirow{2}{*}{$\begin{array}{l}M I \\
\text { NA }\end{array}$} & \multirow{2}{*}{$\frac{\text { PTEN mutation }}{\text { NA }}$} & \multirow{2}{*}{$\frac{\text { p53 mutation }}{-}$} \\
\hline 1 & UCC & & & & & & \\
\hline 2 & UCC & 70 & Weakly PE & $1 \mathrm{~A}$ & + & + & - \\
\hline 3 & UCC & 68 & NA & NA & NA & NA & - \\
\hline 4 & UCC & 67 & Atrophic & $3 \mathrm{~A}$ & - & + & - \\
\hline 5 & UCC & 80 & Atrophic & $1 \mathrm{~B}$ & - & - & + \\
\hline \multirow[t]{2}{*}{6} & UCC & 77 & EIC/tumor & $2 \mathrm{~B}$ & - & - & + \\
\hline & USC & & & & - & - & + \\
\hline 7 & UCC & 68 & Atrophic & $3 \mathrm{~A}$ & - & - & - \\
\hline 8 & UCC & 56 & Atrophic & $1 \mathrm{~B}$ & - & - & - \\
\hline \multirow[t]{2}{*}{9} & UCC & 70 & EIC/atrophic & $1 \mathrm{~A}$ & - & - & + \\
\hline & USC & & & & - & - & + \\
\hline \multirow[t]{2}{*}{10} & UCC & 54 & Atrophic & $1 \mathrm{~B}$ & + & + & + \\
\hline & UEC & & & & + & + & + \\
\hline 11 & UCC & 74 & Atrophic & 2B & - & - & - \\
\hline \multirow[t]{2}{*}{12} & UCC & 33 & CAH & $3 \mathrm{~A}$ & - & - & - \\
\hline & UEC & & & & - & - & - \\
\hline 13 & UCC & 68 & Atrophic & $2 \mathrm{~B}$ & - & - & - \\
\hline \multirow[t]{3}{*}{14} & UCC & 84 & EIC/atrophic & $3 \mathrm{~A}$ & - & - & + \\
\hline & MCA & & & & - & - & + \\
\hline & MSA & & & & - & - & + \\
\hline 15 & UCC & 74 & Weakly PE & $2 \mathrm{~B}$ & - & - & - \\
\hline 16 & UCC & 80 & Atrophic & $3 \mathrm{~A}$ & - & - & - \\
\hline
\end{tabular}

Microsatellites are highly repetitive segments of DNA consisting of 2-5 nucleotides located primarily in the noncoding regions of the genome. MI was first described in hereditary nonpolyposis colon cancer, ${ }^{27}$ where in the presence of mutations in the DNA mismatch repair genes, the tumor DNA exhibits novel microsatellite alleles. Previous studies have demonstrated MI positivity in $17-25 \%$ of UEC. ${ }^{6-8}$ It is rare to find MI in USC. ${ }^{28}$ Risinger et $a l^{29}$ analyzed seven type II (serous or clear cell) for MI and were unable to demonstrate the MI phenotype in any of the tumors. In contrast, MI was identified in six endometrioid endometrial adenocarcinoma in the same study. Similarly, all 34 serous endometrial adenocarcinoma evaluated for MI by Tashiro et $a 1^{28}$ were found to be negative. The current study shows MI positivity in two cases (14\%) of UCC analyzed. One case was a pure UCC and the other a mixed 

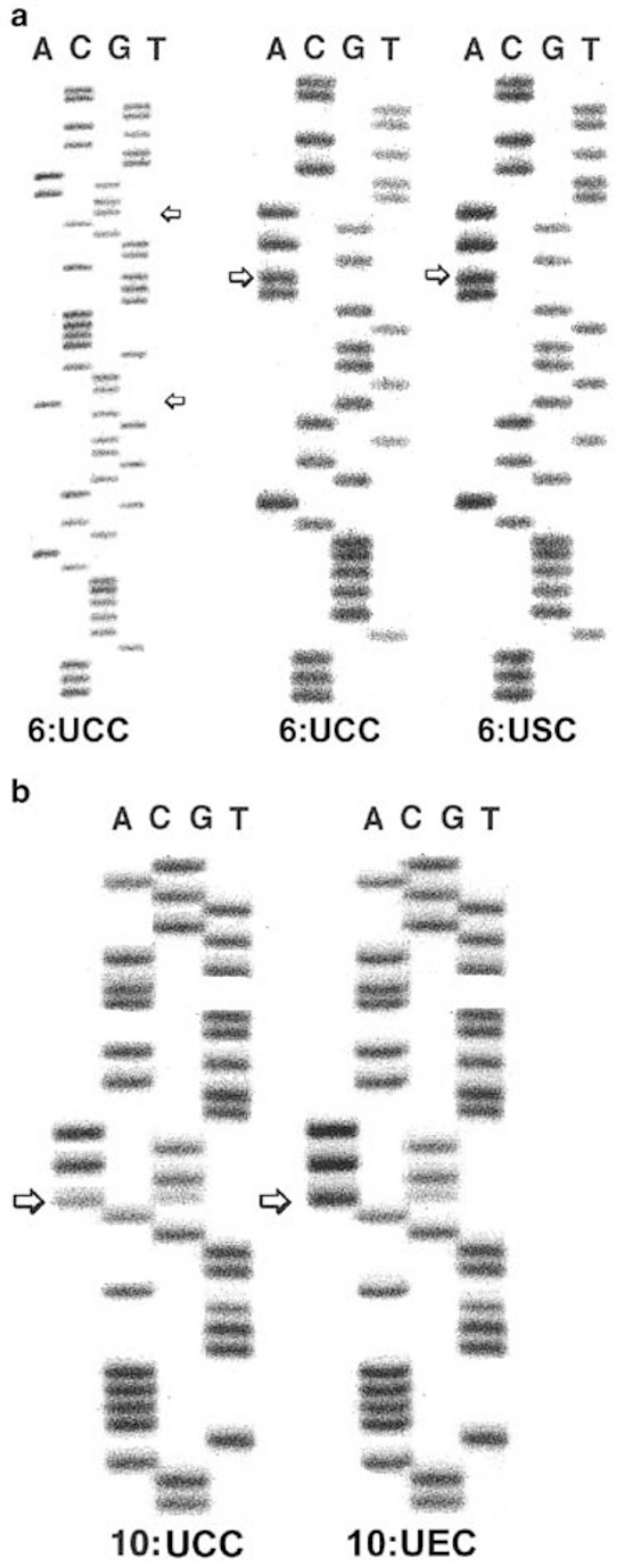

Figure 4 p53 exon 8 sequence analysis. (a) p53 exon 8 sequence analysis (antisense) in case 6 (mixed UCC/USC) demonstrates a frameshift mutation (16 bp deletion and $1 \mathrm{bp}$ insertion) from codon 290 to 295 in both components; case 2 demonstrates wildtype exon 8 sequence for comparison. (b) p53 exon 8 sequence analysis (antisense) in case 10 (mixed UCC/UEC) demonstrates a missense mutation ( $\mathrm{C}$ to $\mathrm{T}$ transition), resulting in arginine (CGC) to cysteine (TGC) substitution in both components.

UCC/UEC. In addition, both the tumors with MI showed PTEN mutations: one missense and one nonsense mutation. There is no known morphologic precursor of UCC and therefore the relationship of PTEN mutation to MI in the single pure case of UCC is unclear.

Recent studies have demonstrated a significantly higher incidence of $p 53$ gene mutation in USC compared to UEC. ${ }^{3,9,10}$ The presence of a mutation is generally associated with strong and diffuse immunohistochemical expression of the p53 protein. We found strong expression of p53 protein in $30 \%$ of the tumors, the majority being mixed type. Our results are in agreement with those of Lax et $a l,{ }^{11}$ who found strong expression of p53 protein in only $25 \%$ of UCC. Mutations in the $p 53$ gene were confirmed in four of the five cases with strong immunohistochemical expression of p53 protein in this study. Interestingly, p53 mutations were identified in only one (9\%) of the pure UCC. This finding, although limited by the small sample size, suggests that the molecular pathways for UCC probably do not involve p53 gene mutations with the same frequency observed in USC (greater than 90\%). More cases of pure UCC need to be evaluated to ascertain the true frequency of p53 mutations in these tumors. The presence of identical mutations in the UCC and non-UCC components of the mixed tumors supports a monoclonal origin of the two components and suggests that the morphological divergence occurred after neoplastic transformation. We considered the possibility of crosscontamination during the microdissection procedure as a possible reason for the presence of identical mutations in the clear cell and the non-clear cell components of the mixed tumors. In case 6, although identical mutations in the p53 gene were identified (Table 3) in the two components, different $\mathrm{LOH}$ patterns were noted (Table 2). The UCC component showed LOH at the locus D18S58, while the serous component had $\mathrm{LOH}$ at locus D2S147. This clearly demonstrates the integrity of the microdissection technique in our study. Furthermore, it provides additional support for the monoclonal origin of the two components and suggests that the subsequent morphologic divergence is associated with underlying genetic changes.

In the nine cases of pure UCC, only three cases $(33 \%)$ showed mutations in the genes tested or any evidence of MI. These results suggest that in the pure phenotype, there is genetic heterogeneity. Sampling is always an issue and can account for some of the genetic variability observed in our cases. However, the difference in the prevalence of mutations in the pure and the mixed type is notable (33 vs $80 \%$ ), although the numbers are not large enough to permit a statistical analysis. A review of the histologic and clinical features of the three pure cases that showed mutations did not reveal any significant difference from those pure tumors that lacked any detectable mutations (Table 4). It would be interesting to see similar studies with molecular analysis and clinical follow-up to determine if the presence of these mutations has any prognostic significance.

In conclusion, we have studied 16 cases of UCC of the endometrium for mutations in PTEN gene, p53 gene and the presence of MI. Our results demonstrate that the majority of pure UCC do not show mutations in the two genes studied in this report. In tumors with a mixed histologic appearance, our data support a monoclonal origin for the clear cell and 
the non-clear cell components. This study, although small, raises some important questions regarding the pathogenesis of UCC and the need to separate pure from mixed clear cell carcinomas in future clinicopathologic studies. As more studies on the molecular mechanisms underlying this tumor are revealed, we may be able to better understand the pathogenesis of this tumor. The absence of mutations in the PTEN gene and the p53 gene in the majority of pure UCC should prompt a search for additional genetic changes in this variant of endometrial carcinoma, in order to further our understanding of its pathogenesis and biological behavior.

\section{Acknowledgements}

We thank Robert Santoianni for his excellent technical assistance in preparing the photomicrographs.

\section{References}

1 Bokhman JV. Two pathogenetic types of endometrial carcinoma. Gynecol Oncol 1983;15:10-17.

2 Koul A, Willen R, Bendahl PO, et al. Distinct sets of gene alterations in endometrial carcinoma implicate alternate modes of tumorigenesis. Cancer 2002;94: 2369-2379.

3 Lax SF, Kendall B, Tashiro H, et al. The frequency of p53, K-ras mutations, and microsatellite instability differs in uterine endometrioid and serous carcinoma: evidence of distinct molecular genetic pathways. Cancer 2000;88:814-824.

4 Sherman ME. Theories of endometrial carcinogenesis: a multidisciplinary approach. Mod Pathol 2000;13: 295-308.

5 Tashiro H, Blazes MS, Wu R, et al. Mutations in PTEN are frequent in endometrial carcinoma but rare in other common gynecological malignancies. Cancer Res 1997;57:3935-3940.

6 Catasus L, Machin P, Matias-Guiu X, et al. Microsatellite instability in endometrial carcinomas: clinicopathologic correlations in a series of 42 cases. Hum Pathol 1998;29:1160-1164.

7 Burks RT, Kessis TD, Cho KR, et al. Microsatellite instability in endometrial carcinoma. Oncogene 1994;9:1163-1166.

8 Duggan BD, Felix JC, Muderspach LI, et al. Microsatellite instability in sporadic endometrial carcinoma. J Natl Cancer Inst 1994;86:1216-1221.

9 Sherman ME, Bur ME, Kurman RJ. p53 in endometrial cancer and its putative precursors: evidence for diverse pathways of tumorigenesis. Hum Pathol 1995; 26:1268-1274.

10 Moll UM, Chalas E, Auguste M, et al. Uterine papillary serous carcinoma evolves via a p53-driven pathway. Hum Pathol 1996;27:1295-1300.

11 Lax SF, Pizer ES, Ronnett BM, et al. Clear cell carcinoma of the endometrium is characterized by a distinctive profile of p53, Ki-67, estrogen, and progesterone receptor expression. Hum Pathol 1998;29: $551-558$.
12 Giri PG, Schneider V, Belgrad R. Clear cell carcinoma of the endometrium: an uncommon entity with a favorable prognosis. Int J Radiat Oncol Biol Phys 1981;7:1383-1387.

13 Cirisano. Jr FD, Robboy SJ, Dodge RK, et al. The outcome of stage I-II clinically and surgically staged papillary serous and clear cell endometrial cancers when compared with endometrioid carcinoma. Gynecol Oncol 2000;77:55-65.

14 Kurman RJ, Scully RE. Clear cell carcinoma of the endometrium: an analysis of 21 cases. Cancer 1976;37:872-882.

15 Bafna UD, Tasneem R. Long-term survival of an advanced stage clear cell carcinoma of the endometrium occurring in a young woman. J Obstet Gynaecol 2002;22:451-452.

16 Carcangiu ML, Chambers JT. Early pathologic stage clear cell carcinoma and uterine papillary serous carcinoma of the endometrium: comparison of clinicopathologic features and survival. Int J Gynecol Pathol 1995;14:30-38.

17 Abeler VM, Kjorstad KE. Clear cell carcinoma of the endometrium: a histopathological and clinical study of 97 cases. Gynecol Oncol 1991;40: 207-217.

18 Silverberg SG, De Giorgi LS. Clear cell carcinoma of the endometrium. Clinical, pathologic, and ultrastructural findings. Cancer 1973;31:1127-1140.

19 Sakuragi N, Hareyama H, Todo Y, et al. Prognostic significance of serous and clear cell adenocarcinoma in surgically staged endometrial carcinoma. Acta Obstet Gynecol Scand 2000;79:311-316.

20 Photopulos GJ, Carney CN, Edelman DA, et al. Clear cell carcinoma of the endometrium. Cancer 1979;43:1448-1456.

21 Malpica A, Tornos C, Burke TW, et al. Low-stage clearcell carcinoma of the endometrium. Am J Surg Pathol 1995;19:769-774.

22 Kanbour-Shakir A, Tobon H. Primary clear cell carcinoma of the endometrium: a clinicopathologic study of 20 cases. Int J Gynecol Pathol 1991;10:67-78.

23 Christopherson WM, Alberhasky RC, Connelly PJ. Carcinoma of the endometrium: I. A clinicopathologic study of clear-cell carcinoma and secretory carcinoma. Cancer 1982;49:1511-1523.

24 Li J, Yen C, Liaw D, et al. PTEN, a putative protein tyrosine phosphatase gene mutated in human brain, breast, and prostate cancer. Science 1997;275:19431947.

25 Levine RL, Cargile CB, Blazes MS, et al. PTEN mutations and microsatellite instability in complex atypical hyperplasia, a precursor lesion to uterine endometrioid carcinoma. Cancer Res 1998;58: 3254-3258.

26 Yaginuma Y, Yamashita T, Ishiya T, et al. Abnormal structure and expression of PTEN/MMAC1 gene in human uterine cancers. Mol Carcinogen 2000;27: 110-116.

27 Kinzler KW, Vogelstein B. Lessons from hereditary colorectal cancer. Cell 1996;87:159-170.

28 Tashiro H, Lax SF, Gaudin PB, et al. Microsatellite instability is uncommon in uterine serous carcinoma. Am J Pathol 1997;150:75-79.

29 Risinger JI, Berchuck A, Kohler MF, et al. Genetic instability of microsatellites in endometrial carcinoma. Cancer Res 1993;53:5100-5103. 